\title{
Metabolic syndrome components and face shape variation in elderly
}

\section{Componentes da síndrome metabólica e variação na forma da face em idosos}

\author{
Lélia Lessa Teixeira Pinto ${ }^{1}$ \\ (iD https://orcid.org/0000-0002-2923-6928 \\ Thaís Barros do Carmo ${ }^{1}$ \\ (D) https://orcid.org/0000-0002-5063-8067 \\ Alessandra Santos Sales ${ }^{1}$ \\ (D) https://orcid.org/0000-0002-6346-6110 \\ Lorena Andrade Nunes 1 \\ (D) https://orcid.org/0000-0002-7453-7666 \\ Cezar Augusto Casotti' \\ (D) https://orcid.org/0000-0001-6636-8009
}

\begin{abstract}
The aim of this study was to identify the metabolic syndrome (MS) components mostly influencing face shape in elderly individuals. This is a cross-sectional epidemiological study carried out with elderly individuals living in Aiquara County, Bahia State. Facial images at frontal view and MS were classified according to the National Cholesterol Education Program's Adult Treatment Panel III (revised version). Discriminant function, cross validation and distance Mahalanobis $\mathrm{D}^{2}$ were used to extract face shape variations due to MS. Principal Component Analysis (PCA) was used to evaluate MS components' influence on face shape. The total of 193 elderly individuals were selected; there were significant differences in face shape due to MS ( $\mathrm{p}<0.01)$ in both sexes. PCA 1 showed HDL-C in men, which accounted for $37 \%$ of the total variation. HDL-C in biplot is associated with individuals who do not have MS and with elderly individuals with MS - there was correlation between waist circumference and triglycerides. PCA 1 represented $33.2 \%$ of the total variation in women; this outcome is explained by triglycerides. There was association between blood glucose and waist circumference in biplot. HDL-C is related to women who do not have MS. Facial variations affected by MS did not derive from the action of any of the MS components, but from the association between them. Thus, geometric morphometrics emerges as a promising method that makes it possible identifying heart disease and metabolic risk factors according to face shape features.
\end{abstract}

Key words: Aged; Facial asymmetry; Metabolic syndrome.

Resumo - Objetivou-se identificar dentre os componentes da sindrome metabólica (SM) o que mais interfere na forma da face em idosos. Trata-se de um estudo epidemiológico, transversal, realizado com idosos residentes de Aiquara-BA. Foram obtidas imagens faciais da vista frontal e a $S M$ foi classificada segundo o National Cholesterol Education Program's Adult Treatment Panel III, revisado. A partir da função discriminante, validação cruzada e a distância $D^{2}$ Mahalanobis, foram extraídas as variaçôes da forma em função da SM. Para avaliar a influência dos componentes da SM na forma da face, utilizou-se a Análise de Componentes Principais (ACP). Participaram 193 idosos e foram identificadas diferenças significativas na forma da face em relação a $S M(p<0,01)$ em a mbos os sexos. Para os homens, o ACP 1 foi o HDL-C, este explicou 37\% da variação total. Pelo biplot, o $H D L-C$ está associado aos indivíduos que não possuem SM e em idosos com SM, houve uma correlação entre a circunferência da cintura e os triglicerídeos. Para as mulheres, o ACP 1 representou 33,2\% da variação total, explicado pelos triglicerídeos. Pelo biplot, houve uma relação entre glicose e circunferência da cintura. Nas mulheres, o HDL-C está relacionado com quem não tem SM. As variaçôes faciais acometidas pela $S M$, não foram decorrentes da ação de um dos componentes da mesma, mas das relaçôes entre eles. Assim, a morfometria geométrica se mostra como método promissor e possibilita identificar a partir da forma da face fatores de risco cardiovascular e metabólico.

Palavras-chave: Assimetria facial; Idoso; Sindrome metabólica.
1 Universidade Estadual do Sudoeste da Bahia. Programa de Pós-Graduação em Enfermagem e Saúde. Jequié, BA. Brasil.

Received: May 30, 2020 Accepted: October 09, 2020

How to cite this article Pinto LLT, Carmo, TB, Sales AS, Nunes $L A$, Casotti CA. Metabolic syndrome components and face shape variation in elderly. Rev Bras Cineantropom Desempenho Hum 2020, 22:e74390. DOl: http://dx.doi.org/10.1590/19800037.2020v22e74390

Copyright: This work is licensed under a Creative Commons Attribution 4.0 International License. 


\section{INTRODUCTION}

The urbanization process has led to changes in socioeconomic and cultural profiles of populations, and it has also caused changes in individuals' lifestyle and health conditions. Thus, this process has increased the prevalence of non-transmissible diseases ${ }^{1}$.

Non-transmissible diseases, mainly heart diseases and diabetes, are among the main causes of death; they account for $70 \%$ of them. Yet, high income countries have reduced their heart-related mortality rates, whereas mid- and low-income countries have been trying to reduce them, but still they account for the highest rates of $\mathrm{it}^{2}$.

Metabolic Syndrome (MS) is among factors posing risk for the development of heart diseases and type-II diabetes mellitus; besides, it encompasses a set of complex symptoms featured by pathophysiological changes that take place at the same time ${ }^{3}$. Central obesity, dyslipidemias, high blood pressure and hyperglycemia are groups of components defining $\mathrm{MS}^{4}$.

Lack of consensus about criteria to define MS diagnostics limits estimates about the global prevalence of it and impairs comparisons between previous studies. However, reports have shown that MS prevalence has been growing in all groups, mainly due to global increase in obesity rates ${ }^{5}$.

Overall, obesity has been seen as indicator of metabolic abnormalities that compose MS and that rise the risk of developing heart diseases, other comorbidities and death. Aging is another risk factor among conditions favoring the previously mentioned outcomes ${ }^{6}$.

Accordingly, anthropometric indicators have been used as MS indicators in order to make the identification of this condition easier in the clinical practice and to allow preventing the early development of heart diseases and death caused by them ${ }^{7}$. Recently, studies have been using different techniques to identify face features associated with health conditions; they can also provide accurate results about outcomes and future health conditions ${ }^{8-11}$.

Geometric morphometrics is among these techniques, it allows quantifying face shape variations, testing hypotheses and identifying their causes ${ }^{12}$. This technique can be applied to screen certain diseases and to contribute to treatment strategies; however, it is necessary confirming the likelihood of its use to identify diseases given the scarcity of studies in this field ${ }^{10}$.

Morphological face features have been related to diseases composing the metabolic syndrome, such as diabetes mellitus ${ }^{11}$, high blood pressure ${ }^{10}$ and obesity 9 . Thus, the aim of the present study was to identify the metabolic syndrome components mostly influencing face shape in elderly individuals.

\section{METHOD}

Epidemiological cross-sectional home-based study conducted from January to March 2018. The study is aligned to a prospective cohort known as "Health condition and life-style of elderly individuals living in a small-sized 
county". The study was carried out in Aiquara County, Central-South Bahia State.

The research encompassed individuals of both sexes in the age group 60 years, or older. Inclusion criteria were individuals who have slept three nights, or more, at home and who live in the urban zone of the county. Exclusion criteria were elderly individuals with low visual and hearing acuity, and with low cognitive deficit (assessed through Mini-Mental State Examination $)^{13}$ - which could compromise research development; institutionalized elderly individuals and individuals who did not take the picture for the morphometric analysis.

The age and sex of the participants were taken into account. Metabolic syndrome was assessed based on criteria set by the National Cholesterol Education Program's Adult Treatment Panel III (NCEP-ATP III), which was revised by the American Heart Association. These criteria consist in the combination of at least three components among the five established ones: 1) abdominal obesity (waist circumference) - >88 cm for women and $>102$ for men; 2) triglycerides - $\geq 150 \mathrm{mg} / \mathrm{dL}$ or patients subjected to drug treatment for high triglycerides; 3) HDL-C: $<50 \mathrm{mg} / \mathrm{dL}$ and $<40 \mathrm{mg} / \mathrm{dL}$ for men or patients subjected to drug treatment for reduced HDL-C; 4) blood pressure - $\geq 130 \mathrm{mmHg}$ systolic blood pressure and/or $\geq 85 \mathrm{mmHg}$ diastolic blood pressure or patients subjected to antihypertensive treatment; 5) fasting blood glucose $-\geq 100 \mathrm{mg} / \mathrm{dL}$ or patients subjected to drug treatment for high blood sugar ${ }^{4,14,15}$.

Waist circumference $(\mathrm{cm})$ regarded the mid-point between the iliac crest and the last rib. Measurements were taken with flexible and inelastic measuring tape (Sanny) - the appraiser was positioned in front of the patient ${ }^{16}$. Blood pressure was measured with Omron device (HEM-7320) based on recommendations in the $7^{\text {th }}$ Brazilian High Blood Pressure Guidelines - it was measured three times at the same upper limb; the mean value of the three measurements was used in the experiment ${ }^{17}$.

Blood collection, storage, adjustment and processing were carried out by professionals from Laboratório Central Municipal de Vitória da Conquista (LACEM). Elderly individuals were instructed to fast overnight for a period of 8 to 12 hours. Biochemical variables (Triglycerides, HDL-C, Glycemia) were measued and processed through colorimetric enzymatic reactions and dosed in Beckman Coulter ${ }^{\circledR}$ AU 680 Automatized Analyzer through spectrophotometry.

Geometric morphometrics measurements were taken based on the means recorded for the 5 facial images at frontal view taken from elderly individuals; this procedure followed the standard suggested by Nunes et al. ${ }^{10}$. Data were subjected to Procruste superposition analysis based on coordinates generated from landmarks and semilandmarks in order to eliminate scale effects, rotation and orientation, as well as to reach consensus about face shape and to apply ANOVA test to identify measurement mistakes related to the meter. Thus, measurements were taken in triplicate $^{18}$ (Figure 1). 
A

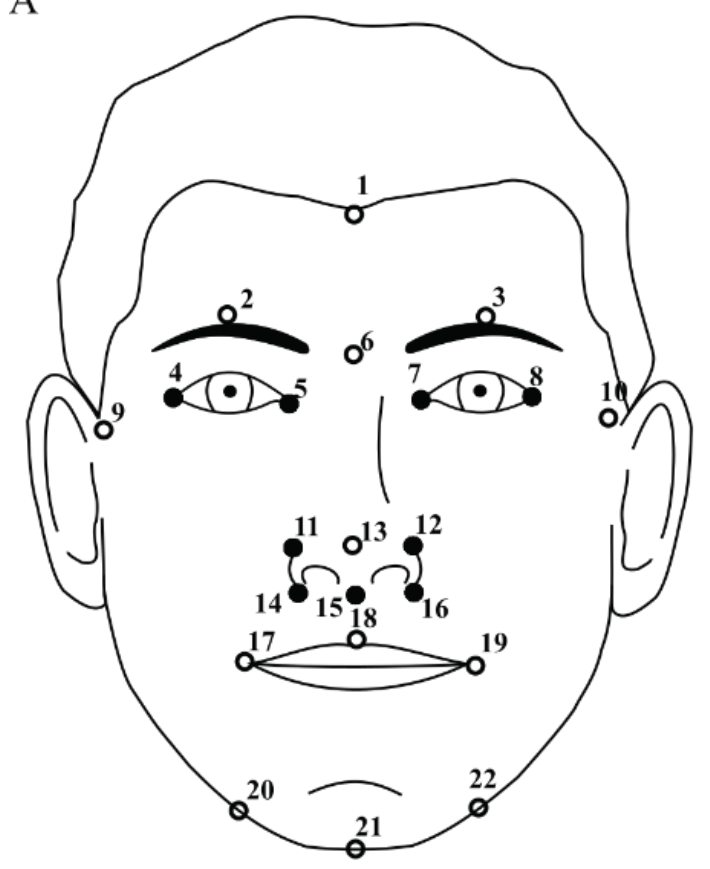

$\mathrm{B}$

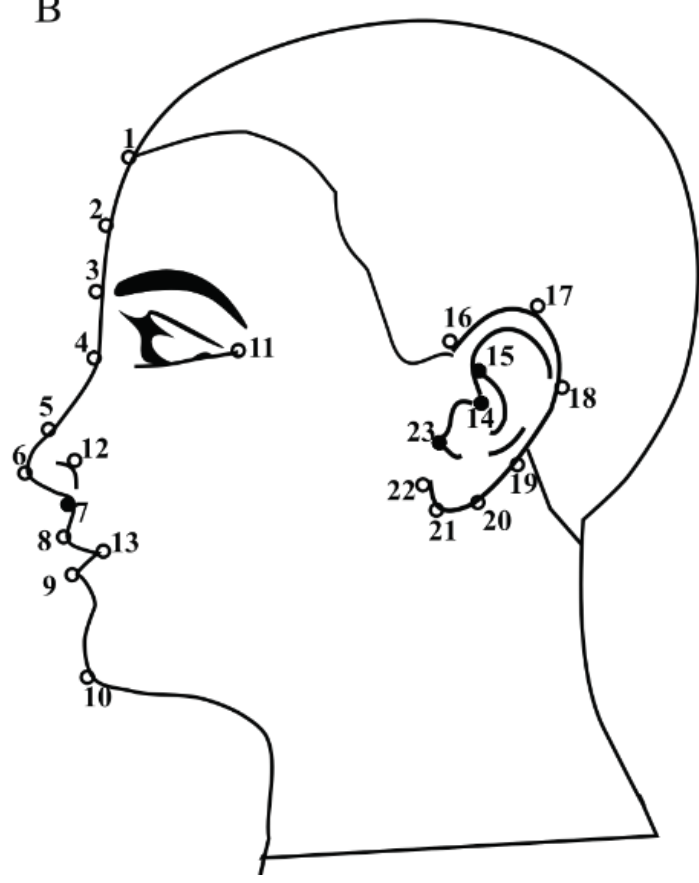

Figure 1. Frontal (A) and lateral view (B) image with the location of landmark (filled dots) and semilandmark points (empty dot) used in face differentiation ${ }^{10}$.

Regression analysis was applied to allometry and teeth loss, MANOVA was used to identify differences associated with sexual dimorphism. Discriminant function, cross validation and Mahalanobis distance $\mathrm{D}^{2}$ were used to extract face shape variations due to metabolic syndrome - this distance was related to the other MS components. These analyses were conducted in MorphoJ software (Manchester, England) ${ }^{19}$.

Population featuring was introduced through descriptive analysis by using absolute and relative frequencies. Principal component analysis (PCA) was used to assess the influence of metabolic syndrome components on face shape based on the correlation matrix of variables: blood pressure, blood glucose, triglycerides, HDL-C and waist circumference. This correlation allowed determining components according to their influence on total variation.

PCA is used to assess a larger number of variable combinations and to explain them through common inherent dimensions (factors), i.e., this analysis aims at gathering information found in a large number of original variables within a smaller set of statistical variables (factors) with minimal information $\operatorname{loss}^{20}$.

The present study was approved by the Research Ethics Committee of Southeastern Bahia State University and approved by Opinion n. 1.575.825, CAAE 56017816.2.0000.0055.

\section{RESULTS}

In total, 193 elderly individuals participated in the study; $62.7 \%(\mathrm{n}=121)$ of them were women and $37.3 \%(n=72)$ were men. The mean age of par- 
ticipants was $71.66 \pm 7.69$; participants' age ranged from 60 to 92 years.

There were no significant results recorded for measurement mistake, allometry and teeth loss ( $p>0.05)$; however, there were significant differences recorded for sexual dimorphism ( $\mathrm{p}<0.01)$. Significant differences in MS were recorded for both sexes $(\mathrm{p}<0.01)$ after the face shape variation analysis.

Based on PCA - supported by face shape variables and by MS components applied to men -, it was possible observing that these variables explained $37 \%$ variation in the analyzed data, which were represented by HDL-C. HDL-C (Figure 2) in biplot is associated with individuals who do not have MS, i.e., people who present lower HDL-C are more likely to present MS. Furthermore, it is possible identifying elderly individuals with MS through biplot, since there is correlation between waist circumference and triglycerides.

PCA represented $33.2 \%$ total variation in women, which was explained by the triglycerides value. It means that the higher the triglycerides value, the greater the possibility of these individuals to have MS. Besides, the biplot (Figure 3) allowed assessing the association between blood sugar and waist circumference. Moreover, it was possible observing that HDL-C was related to women without MS, similarly to what was observed for men.

\section{DISCUSSION}

Based on results in the present study, the triglycerides/abdominal obesity ratio was the metabolic syndrome component mostly influencing face shape in male elderlies. With respect to women, triglycerides was the component standing out among the others, despite the blood sugar/obesity ratio. Both men and women were influenced by HDL-C, which was associated with elderly individuals without MS.

Previous studies based on the use of geometric morphometrics in human face analysis also observed the association of face shape features with

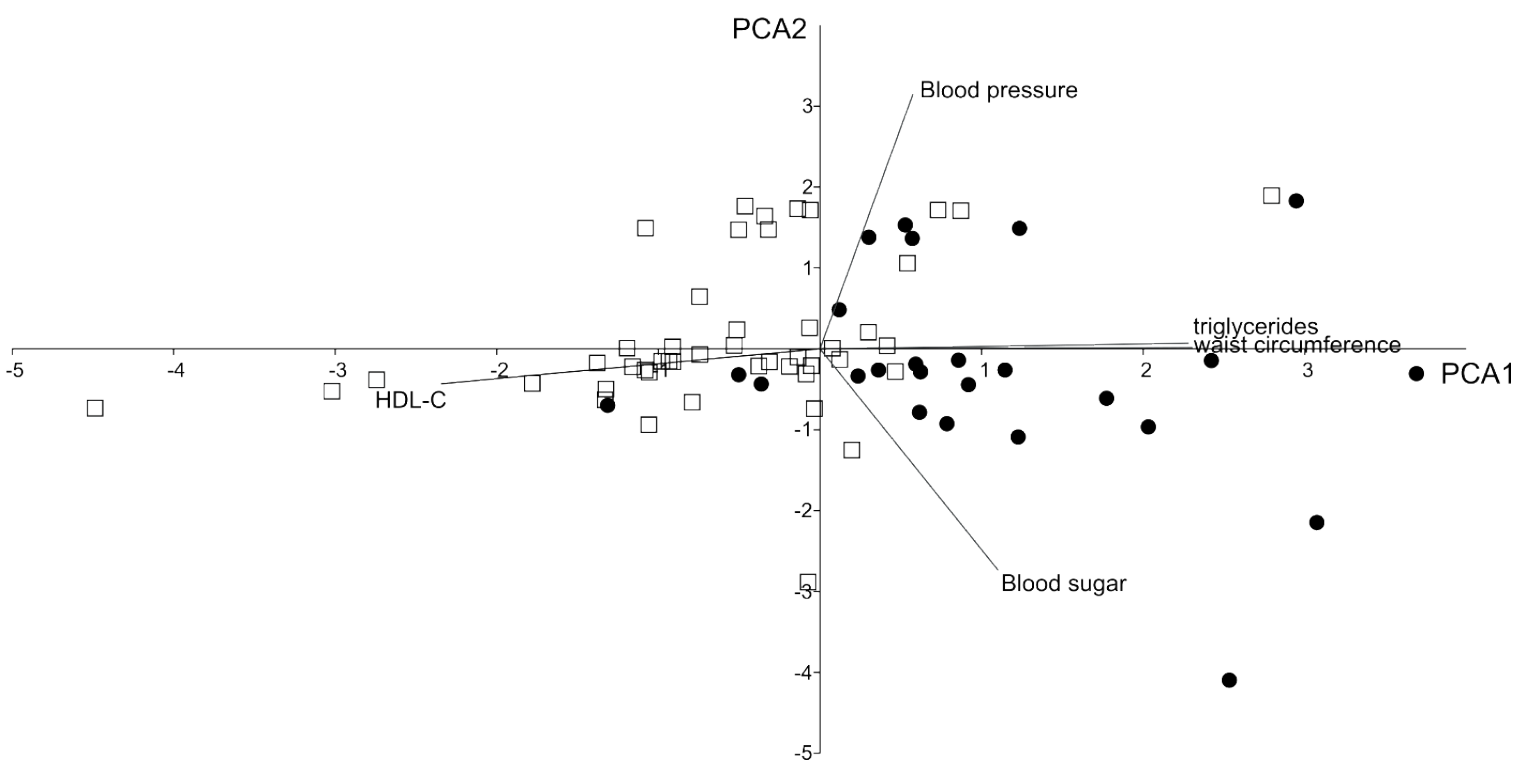

Figure 2. Biplot highlighting Metabolic Syndrome components influence on face shape variation in men with (circles) and without (squares) this syndrome. Aiquara, Bahia State, 2018. 


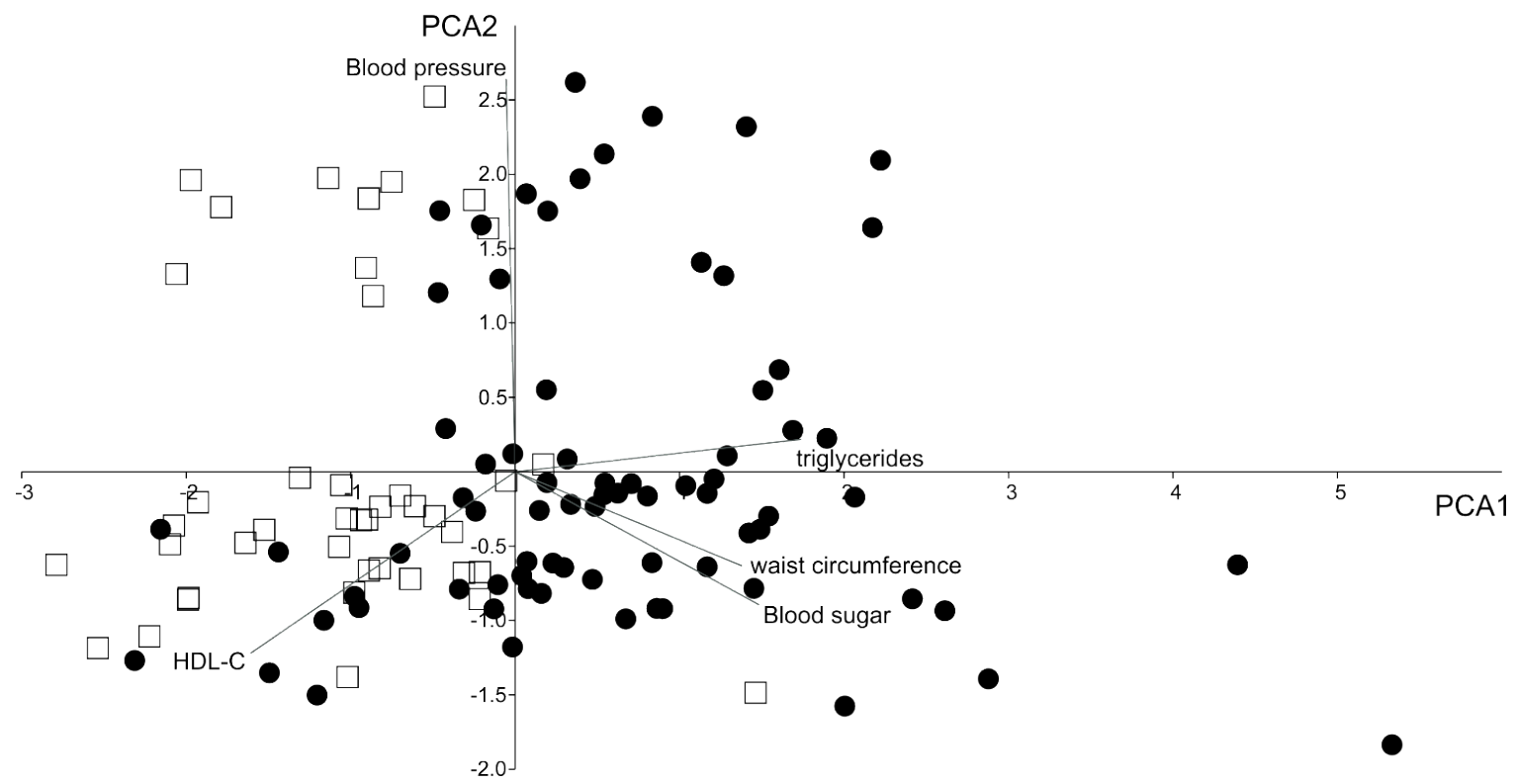

Figure 3. Biplot highlighting metabolic syndrome components influencing face shape variation in women with (circles) and without (squares) MS. Aiquara, bahia State, 2018.

pathologies encompassing MS diagnostics, such as obesity ${ }^{8,9}$, high blood pressure $^{10}$ and diabetes mellitus ${ }^{10,11}$.

Studies have suggested that face adiposity is closely related to body adiposity. Face adiposity features allow inferring the negative health condition outcomes due to negative health outcomes caused by visceral fat accumulation ${ }^{8,21}$.

Obesity can be measured through anthropometric indicators; when it comes to MS, waist circumference can be used as central obesity indicator among criteria for MS diagnostics. Such excess of body fat can be one of the risk factors for the predisposition to MS components, such as insulin resistance, high blood pressure and dyslipidemia, as well as to the syndrome itself 5 .

There may be metabolic complications in adipose tissue, such as lipolysis inhibition deregulation due to insulin resistance, which result in fatty acids and glycerol release, leptin release (adipokines that increase the risk of heart disease) and decreased adiponectin (anti-inflammatory and anti-atherogenic adipokine), and chronic inflammation in the organism ${ }^{3}$.

A prospective study showed that metabolically healthy obese individuals significantly increased their likelihood of developing heart disease risk factors, such as type-II diabetes mellitus, low HDL-C or use of lipid-lowering drugs, and high triglycerides after 5.6-year and 10.9-year follow-up ${ }^{6}$. Overweight/obesity is a relevant factor for lipid concentration increase, mainly cholesterol and triglycerides ${ }^{22}$. Unlike cholesterol, triglycerides can be degraded by most of the cells; thus, evidences have shown that triglycerides-rich lipoproteins seem to promote atherosclerosis and heart diseases ${ }^{22,23}$.

Overall, middle-aged men (36-65 years) are more prone to present risk factors and more susceptible to abdominal obesity and metabolic 
syndromes. Women, in their turn, present this framework 10 to 15 years later, due to the effects from feminine hormone losses ${ }^{4}$. However, age increases the prevalence of heart diseases and the number of deaths caused by them in both sexes ${ }^{6}$.

Blood sugar in women was related to obesity and triglycerides; according to Venturini et al. ${ }^{24}$, hypertriglyceridemia is more frequent in women and blood sugar only increased in the female sex. It is likely associated with the fact that obesity is more prevalent among women.

Sexual differences influence de development of type-II diabetes mellitus; women tend to present more overweight/obesity than men due to aging, because these two factors are the main risk condition for diabetes development, besides other biological, psycho-social and behavioral factors ${ }^{25}$.

Besides central obesity and triglycerides, MS men presented blood sugar and blood pressure association with face shape features. Diseases such as diabetes and high blood pressure tend to develop at older ages; they are more prevalent in male elderlies showing morphological features more closely related to these diseases than in women ${ }^{10}$.

HDL cholesterol in both sexes was associated with elderly individuals who did not have MS; it can be likely explained by the "protector" effect of HDL-C in comparison to other MS components. High blood pressure, blood sugar, triglycerides and obesity have atherogenic functions, whereas HDL-C play an antiatherogenic role, since one of its function is the "reverse cholesterol transport", i.e., it takes cholesterol from the periphery (tissues and vascular walls) back to the liver in order to be excreted ${ }^{26,27}$.

Thus, it is possible observing that there is no difference between sexes when it comes to face shape variations associated with diseases that can be, in their turn, related to lifestyle and different health conditions between men and women ${ }^{10}$. However, the relationship between MS components can be a gradual condition, i.e., the addictive effect of MS components can have negative influence on health condition, such as increase the risk of heart diseases ${ }^{5}$.

Early and precise MS prevention, identification and treatment are essential to diminish the risk of developing issues related to this syndrome, such as diabetes mellitus, heart diseases and cancer, besides their benefit to the global economy ${ }^{5}$.

The current study presents the same limitation of other cross-sectional studies, namely: causality relations that cannot be established. However, its highlight lies on the fact that it assessed MS components within a single set in order to identify the one mostly influencing the face shape features.

\section{CONCLUSION}

Based on the recorded results, it was possible concluding that central obesity/triglycerides ratio in MS men, and abdominal obesity/blood sugar/ triglycerides ratio in women were the metabolic syndrome components mostly influencing face shape in MS elderly individuals living in Aiquara, 
Bahia State. HDL-C was the component mostly influencing face shape in elderly individuals without MS. Thus, it is possible confirming that the identified face shape variations in MS elderly individuals did not result from MS components, but from the association among them.

Geometric morphometrics emerged as a promising method to identify health conditions, since it allows identifying them based on face shape factors that indicate heart disease and metabolic risk.

\section{COMPLIANCE WITH ETHICAL STANDARDS}

\section{Funding}

This research receives from funding Bahia State Research Support Foundation.

\section{Ethical approval}

Ethical approval was obtained from the local Human Research Ethics Committee - State University of the Southwest of Bahia and the protocol (no. 1.575.825/2016; CAAE 56017816.2.0000.0055) was written in accordance with the standards set by the Declaration of Helsinki.

\section{Conflict of interest statement}

The authors have no conflict of interests to declare.

\section{Author Contributions}

Conceived and designed the experiments: LLTP; CAC and LAN. Performed the experiments: LLTP; TBC and ASS. Analyzed the data: LLTP and LAN. Contributed reagents/materials/analysis tools: LLTP; TBC; ASS; LAN and CAC. Wrote the paper: LLTP; CAC and LAN.

\section{REFERENCES}

1. Patil RR. Urbanization as a Determinant of Health: A Socioepidemiological Perspective. Soc Work Public Health 2014; 29 (4): 335-341.

2. World Health Organization. World Health Statistics 2017: Monitoring Health for the SDGs Sustainable Development Goals. Geneva: World Health Organization. 2017; Disponível em: https://www.who.int/gho/publications/world_health_statistics/2017/en/ [2017 ago 02].

3. Rochlani Y, Pothineni NV, Kovelamudi S, Mehta JL. Metabolic syndrome: pathophysiology, management, and modulation by natural compounds. Ther Adv Cardiovasc Dis 2017; 11 (8): 215-225.

4. Expert Panel on Detection, Evaluation, and Treatment of High Blood Cholesterol in Adults. Executive summary of the third report of the National Cholesterol Education Program (NCEP) expert panel on Detection, Evaluation, and Treatment of high blood cholesterol in adults (Adult Treatment Panel III). JAMA 2001; 285 (19): 2486-2497.

5. O'neill S, O'driscoll L. Metabolic syndrome: a closer look at the growing epidemic and its associated pathologies. Obes Rev 2015; 16 (1): 1-12.

6. Fingeret M, Marques-Vidal P, Vollenweider P. Incidence of type 2 diabetes, hypertension, and dyslipidemia in metabolically healthy obese and non-obese. Nutr Metab Cardiovasc Dis 2018; 28 (10): 1036-1044. 
7. Oliveira CC, Costa ED, Roriz AKC, Ramos LB, Gomes Neto M. Preditores de Síndrome Metabólica em Idosos: Uma Revisão. Int J Cardiovasc Sci 2017; 30 (4): 343-53.

8. Lee BJ, Kim JY. Predicting visceral obesity based on facial characteristics. BMC Complement Altern Med 2014; 14: 248.

9. Mayer C, Windhager S, Schaefer K, Mitteroecker P. BMI and WHR Are Reflected in Female Facial Shape and Texture: A Geometric Morphometric Image Analysis. PLoS One 2017; 12 (1): e0169336.

10. Nunes LA, Jesus AS, Casotti CA, Araújo ED. Geometric morphometrics and face shape characteristics associated with chronic disease in the elderly. Biosci J 2018; 34 (2): 1035-1046.

11. Demayo C, Torres M, Veña C. Face Shapes of Diabetics and Non-Diabetics Described Using Geometric Morphometrics. The Internet J of Endocrinology 2009; 6 (1): 1-6.

12. Adams DC, Rohlf FJ, Slice DE. A field comes of age: geometric morphometrics in the 21st century. Hystrix It. J. Mamm 2013; 24 (1): 7-14.

13. Bertolucci PHF, Brucki SMD, Campacci SR, Juliano Y. The mini-mental state examination in an outpatient population: influence of literacy. Arq. Neuro-Psiquiatr 1994; 52 (1): 01-07.

14. Grundy SM, Cleeman JI, Daniels SR, Donato KA, Eckel RH, Franklin BA, et al. Diagnosis and management of the metabolic syndrome an American Heart Association/National Heart, Lung, and Blood Institute scientific statement. Circulation 2005; 112 (17): 2735-2752.

15. I Diretriz Brasileira de Diagnóstico e Tratamento da Síndrome Metabólica. Arq Bras Cardiol 2005; 84 (Suppl. 1).

16. Callaway WC, et al. Circumferences. In: Lohman TG, Roche AF, Martorell R, editors. Anthropometric Standardization Reference Manual. Champaign: Human Kinetics; 1988. p. 39-54.

17. Malachias MVB, Souza WKSB, Plavnik FL, Rodrigues CIS, Brandão AA, Neves MFT, et al. 7a Diretriz Brasileira de Hipertensão Arterial. Arq Bras Cardiol 2016; 107 (3Supl.3):1-83.

18. Palmer AR. Fluctuating asymmetry analyses: A primer. In: Markow TA, editor. Developmental Instability: Its Origins and Evolutionary Implications. Dordrecht. The Netherlands: Kluwer Academic Publishers 1994. p. 335-364.

19. Klingenberg CP. MorphoJ: In integrated software package for geometric morphometrics. Mol Ecol Resour 2011; 11 (2): 353-357.

20. Hair Junior JF et al. Análise Multivariada de dados. Tradução Adonai Schlup Sant' Anna. 6. ed. Porto Alegre: Bookman; 2008.

21. De Jager S, Coetzee N, Coetzee V. Facial Adiposity, Attractiveness, and Health: A Review. Front Psychol 2018; 9: 2562.

22. Nordestgaard BG, Varbo A. Triglycerides and cardiovascular disease. Lancet 2014; 384 (9943): 626-635.

23. Kim EH, Lee JB, Kim SH, Jo MW, Hwang JY, Bae SJ, et al. Serum Triglyceride Levels and Cardiovascular Disease Events in Koreans. Cardiology 2015; 131 (4): 228-235.

24. Venturini CD, Engroff P, Gomes I, Carli GA. Prevalência de obesidade associada à ingestão calórica, glicemia e perfil lipídico em uma amostra populacional de idosos do Sul do Brasil. Rev bras geriatr Gerontol 2013; 16 (3): 591-601.

25. Kautzky-Willer A, Harreiter J, Pacini G. Sex and Gender Differences in Risk, Pathophysiology and Complications of Type 2 Diabetes Mellitus. Endocr Rev 2016; 37 (3): 278-316.

26. Chuang TJ, Huang CL, Lee CH, Hsieh CH, Hung YJ, Hung CF, et al. The differences of metabolic synd rome in elderly subgroups: A special focus on young-old, old-old and oldest old. Arch Gerontol Geriatr 2016; 65: 92-97. 
27. Cuchel M, Rohatgi A, Sacks FM, Guyton JR. JCL roundtable: High-density lipoprotein function and reverse cholesterol transport. J Clin Lipidol 2018; 12: 1086-1094.

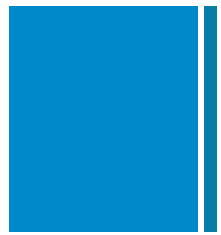

Corresponding author

Lélia L. T. Pinto

Nursing \& Health Postgraduate Program

State University of Southwest Bahia (UESB)

Rua José Moreira Sobrinho, s/n.

Postal Code: 45208-409, Jequiezinho - Jequie, Bahia - Brazil

E-mail: lelia_lessa@hotmail.com 